\title{
Targeting mTOR and elF4E: a feasible scenario in ovarian cancer therapy
}

\author{
Alice Romagnoli ${ }^{1,2}$, Cristina Maracci ${ }^{1}$, Mattia D'Agostino ${ }^{1}$, Anna La Teana ${ }^{1,2}$, Daniele Di Marino ${ }^{1,2}$ \\ 'Department of Life and Environmental Sciences, Polytechnic University of Marche, Ancona 60131, Italy. \\ ${ }^{2}$ New York-Marche Structural Biology Center (NY-MaSBiC), Polytechnic University of Marche, Ancona 60131, Italy.
}

Correspondence to: Prof. Daniele Di Marino, Department of Life and Environmental Sciences, Polytechnic University of Marche, Via Brecce Bianche, Ancona 60131, Italy. E-mail: d.dimarino@univpm.it

How to cite this article: Romagnoli A, Maracci C, D'Agostino M, Teana AL, Marino DD. Targeting mTOR and elF4E: a feasible scenario in ovarian cancer therapy. Cancer Drug Resist 2021;4:596-606. https://dx.doi.org/10.20517/cdr.2021.20

Received: 3 Mar 2021 First Decision: 9 Apr 2021 Revised: 22 Apr 2021 Accepted: 27 Apr 2021 Available online: 11 May 2021

Academic Editor: Paola Perego Copy Editor: Yue-Yue Zhang Production Editor: Yue-Yue Zhang

\begin{abstract}
Ovarian carcinoma is one of the most common causes for cancer death in women; lack of early diagnosis and acquired resistance to platinum-based chemotherapy account for its poor prognosis and high mortality rate. As with other cancer types, ovarian cancer is characterized by dysregulated signaling pathways and protein synthesis, which together contribute to rapid cellular growth and invasiveness. The mechanistic/mammalian target of rapamycin (mTOR) pathway represents the core of different signaling pathways regulating a number of essential steps in the cell, among which protein synthesis and the eukaryotic initiation factor 4E (elF4E), the mRNA cap binding protein, is one of its downstream effectors. elF4E is a limiting factor in translation initiation and its overexpression is a hallmark in many cancers. Because its action is regulated by a number of factors that compete for the same binding site, elF4E is an ideal target for developing novel antineoplastic drugs. Several inhibitors targeting the mTOR signaling pathway have been designed thus far, however most of these molecules show poor stability and high toxicity in vivo. This minireview explores the possibility of targeting mTOR and elF4E proteins, thus impacting on translation initiation in ovarian cancer, describing the most promising experimental strategies and specific inhibitors that have been shown to have an effect on other kinds of cancers.
\end{abstract}

Keywords: Ovarian cancer, targeted therapy, mTOR pathway, elF4E, inhibitors 


\section{INTRODUCTION}

Ovarian cancer ranks 5 th among the most common causes of cancer death in women worldwide ${ }^{[1]}$. The American Cancer Society estimates that in 2021 about 21,410 new cases of ovarian cancer will be diagnosed and about 13,770 women will die from ovarian cancer in the United States ${ }^{[2]}$. With its overall 5-year survival rate of $30 \%$ for the advanced stage disease ${ }^{[3,4]}$, ovarian cancer has the worst prognosis and the highest mortality rate among gynecologic cancers ${ }^{[5,6]}$. This is due to lack of early diagnosis tools and to the fact that the earliest symptoms are easy to overlook, as they can be confused with other common illnesses. Symptoms usually become more severe by the time the tumor has spread to the surface of the peritoneal cavity, making it much harder to remove by surgical intervention. Indeed, the standard approach in ovarian cancer therapy is surgery, followed by platinum-based chemotherapy, in which cisplatin or carboplatin is combined with $\operatorname{taxanes}^{[7-9]}$.

Despite the initial efficacy of treatment, more than $65 \%$ of patients relapse and develop acquired resistance to platinum-based chemotherapy ${ }^{[10,11]}$. Platinum-based drugs, such as cisplatin, interact with DNA and form intra- or inter-strand DNA cross-links, thereby activating cell death but also DNA repair pathways ${ }^{[12-14]}$. Despite the large number of studies ${ }^{[15,16]}$ and the evidence of the multiple mechanisms of sensitivity and resistance to platinum agents ${ }^{[17]}$, there is an urgent need to target additional mechanisms underlying ovarian cancer platinum-resistance.

Drug resistance is the outcome of the deregulation of several molecular mechanisms, such as drug inactivation, apoptotic stimulation, expression of pro-survival or anti-survival proteins, and alteration of the expression of growth factor receptors ${ }^{[18-21]}$. For the treatment of cisplatin-resistant ovarian cancer, a few options are available with the need to improve treatment efficacy and reduce toxicity ${ }^{[10,22,23]}$.

To overcome these limitations, new analogs of conventional drugs and new therapeutic options are being developed, among which several are currently being tested in clinical trials and others have recently been approved ${ }^{[24,25]}$; however, overcoming drug resistance constantly requires new molecular targets that may provide, in addition to conventional treatment, a more selective therapeutic approach to fight ovarian cancer. To overcome drug resistance and formulate customized individual therapies to improve early diagnosis, research needs to focus on the molecular background of ovarian cancer ${ }^{[11]}$. Translation and signaling pathways represent ideal molecular targets for the development of novel therapeutic strategies. Protein synthesis regulates every aspect of cell phenotype, growth, and metabolism and is tightly controlled by several signaling pathways in response to different external stimuli ${ }^{[26]}$. In human cancer, the dysregulation of these processes has an impact in overall protein synthesis, leading to cancer development and growth ${ }^{[27]}$.

This minireview focuses on the recent research reporting the use of inhibitors of the mechanistic/mammalian target of rapamycin (mTOR) and the eukaryotic translation initiation factor $4 \mathrm{E}$ (eIF4E) as adjuvants in cancer treatment; despite the limited number of studies performed on ovarian cancer cell models, the encouraging results obtained in vitro and in pre-clinical studies with some inhibitors might establish the use in ovarian cancer therapy.

\section{THE MTOR PATHWAY: A POTENTIAL THERAPEUTIC TARGET}

The AKT/mTOR pathway is crucial for the regulation of transcription, translation, cell growth, motility, survival, proliferation, autophagy, and angiogenesis ${ }^{[2,22]}$. Not surprisingly, this pathway is largely deregulated in cancer, where several genes coding for proteins of this axis are frequently mutated, leading to pathway hyperactivation in disease. The majority of the cancer-associated mutations occur in the 
mechanistic/mammalian target of rapamycin $(m T O R)$ gene $^{[30]}$. Because it is found to also be upregulated in ovarian carcinoma ${ }^{[31,32]}$, and its deregulation has been associated with platinum-drug resistance ${ }^{[3,343]}$, mTOR represents an attractive biological target for ovarian cancer therapy.

mTOR is a $289-\mathrm{kDa}$ serine/threonine kinase of the phosphatidylinositol 3-kinase related kinase (PIKK) family. In mammals, mTOR is the core component of two functionally different multi-proteins complexes: mTOR Complex 1 (mTORC1) and mTOR Complex 2 (mTORC2). mTORC1, or rapamycin-sensitive complex, includes the proteins mTOR, mLST8 (or G $\beta \mathrm{L}$ ), and Raptor (regulatory-associated protein of mTOR) and plays a key role in the regulation of mRNA translation and cell growth ${ }^{[31,35]}$. mTORC2 (rapamycin-insensitive complex), consisting of mTOR, mLST8, Rictor (rapamycin-independent companion of $\mathrm{mTOR}$ ), and $\mathrm{mSin} 1$ (or mitogen-activated protein-kinase-associated protein 1), is mainly involved in actin cytoskeleton dynamics [Figure $1 \mathrm{~A}]^{[3,35]}$. $\mathrm{mTOR}$ is a downstream mediator in the phosphatidylinositol3-kinase (PI3K)/AKT pathway; in fact, as a consequence of extracellular stimuli, PIP2 is phosphorylated to produce PIP3 by PI3K. This leads to the activation of the protein kinase B (AKT) via phosphorylation by phosphatidylinositol-dependent kinase 1 and 2 (PDK1 and PDK2) $)^{[36]}$. Activated AKT phosphorylates mTOR on Ser2448, or indirectly by phosphorylation of tuberin protein or tuberous sclerosis complex 2 (TSC2). TSC2 is complexed to TSC1, and, when active, its function is to convert Rheb (Ras homolog enriched in brain)-GTP to Rheb-GDP, inactivating mTORC1. Once phosphorylated, TSC2 loses its affinity for TSC1, leading to activation of $\mathrm{mTORC} 1^{[29,36]}$. Activated mTORC1 phosphorylates the translation regulating factor ribosomal S6 kinase-1 (S6K-1) and the eukaryotic translation initiation factor $4 \mathrm{E}$ (eIF4E) binding family of proteins (4E-BPs) [Figure 1A]. The phosphorylation of S6K-1 leads to the translation of ribosomal proteins, elongation factors, and other proteins involved in the cell cycle, while phosphorylation of $4 \mathrm{E}-\mathrm{BPs}$ causes the release of eIF4E [Figure $1 \mathrm{~B}]^{[37,38]}$. eIF4E is a crucial translation initiation factor, also involved in the onset of a number of cancer types (see discussion below) ${ }^{[39,40]}$.

Contrary to mTORC1, the mechanism by which mTORC2 is activated remains elusive. PI3K stimulates mTORC2 by responding to growth factors. Activated mTORC2 is found to be associated to ribosomes ${ }^{[41]}$, and it directly activates AKT, through phosphorylation of Ser473. This, in turn, activates mTOR, protein kinase C- $\alpha$, and serum- and glucocorticoid-induced protein kinase 1 , acting on actin regulation, as well as on metabolism and cell survival ${ }^{[2,36]}$.

It is clear that the mTOR signaling pathway has an important role in malignancy, as it is frequently hyperactivated in a wide range of tumors, including ovarian cancer ${ }^{[1,42]}$. As a consequence, it represents an attractive candidate for drug design. To date, several inhibitors developed against different proteins of AKT/mTOR pathway are already available at different stages in clinical research, as shown in Table $1^{[39,43]}$. The best characterized mTOR inhibitor is rapamycin (or sirolimus), a macrolide produced by the bacterium Streptomyces hygroscopicus. Rapamycin binds selectively to mTORC1 interacting with a specific binding domain present in $\mathrm{mTORC} 1$, but not in mTORC2. Rapamycin inhibits the serine/threonine kinase activity of mTORC1 with an allosteric mechanism ${ }^{[43]}$. Despite the activity shown by rapamycin in many tumor types $^{[29,44]}$, its clinical use is unsuccessful because of its poor water solubility ${ }^{[29]}$. To overcome this limitation, several analogs of rapamycin, called rapalogs, have been formulated, some of which show encouraging pharmacological features on several cancers. Among rapalogs, there are CCI-779 (temsirolimus), RAD001 (everolimus), and AP23573 (deforolimus) ${ }^{[33,45-49]}$. Some rapalogs are FDA-approved, while others are still in clinical trials ${ }^{[40,43]}$. However, the therapeutic efficacy of rapalogs is hindered by the appearance of negative feedback loops that trigger the activation of AKT in the mTOR pathway ${ }^{[2,39]}$. Second-generation inhibitors are thus being developed, and many of them are already under clinical trial. These compounds have shown promising preliminary results, as dual-specificity inhibitors (targeting both mTOR and PI3K) and inhibitors 
Table 1. Main inhibitors of $m$ TOR and elF4E

\begin{tabular}{|c|c|c|c|c|}
\hline Target & Category & Compound & Clinical trials in ovarian cancer & Ref. \\
\hline \multirow[t]{4}{*}{ mTORC1 } & Antibiotic & Rapamycin & & {$[54]$} \\
\hline & Rapalogs & Temsirolimus & Completed & {$[45,46]$} \\
\hline & & Everolimus & Phase I/II & {$[47,48]$} \\
\hline & & Deferolimus & & [49] \\
\hline \multirow[t]{4}{*}{ mTORC1 and mTORC2 } & Second generations inhibitors & Torin1 & & {$[55]$} \\
\hline & & INK128 & & {$[56]$} \\
\hline & & AZD8055 & & {$[57]$} \\
\hline & & AZD2014 & Phase I/II & {$[58]$} \\
\hline \multirow[t]{5}{*}{$\mathrm{PI} 3 \mathrm{~K}$ and $\mathrm{mTOR}$} & Dual inhibitors & PI-103 & & [59] \\
\hline & & NVP-BEZ235 & Completed & {$[60]$} \\
\hline & & SF1126 & & {$[61]$} \\
\hline & & GNE-477 & & {$[62]$} \\
\hline & & XL765 & & {$[63]$} \\
\hline \multirow[t]{3}{*}{ elF4E expression } & Antisense oligonucleotides & ISIS 183750 & & {$[64]$} \\
\hline & & LY2275796 & & {$[65]$} \\
\hline & miRNA & miR-768-3p & & {$[66]$} \\
\hline \multirow[t]{3}{*}{ elF4E phosphorylation } & MEK inhibitor & U0126 & & {$[67]$} \\
\hline & Small molecule & CGP57380 & & [68] \\
\hline & Natural product & cercosporamide & & [69] \\
\hline \multirow[t]{6}{*}{ elF4E-partners interactions } & Nucleoside analog & Ribavirin & & [70-78] \\
\hline & Small molecules & $4 \mathrm{Ei}-1$ & & {$[79,80]$} \\
\hline & & $4 \mathrm{EGI}-1$ & & {$[81,82]$} \\
\hline & & 4E1RCat & & {$[83]$} \\
\hline & Oligopeptides & GnRH-4EBP fusion peptide & & {$[84]$} \\
\hline & & 4E-BP mimetics peptides & & [85-87] \\
\hline
\end{tabular}

targeting directly mTOR, inhibiting both mTORC1 and mTORC $2^{[37,39,43]}$ [Table 1]. Among the downstream effectors of mTOR, the p70S6 kinase is also implicated in fundamental cellular processes, such as cell growth and proliferation ${ }^{[38]}$. p70S6k, together with $4 \mathrm{E}-\mathrm{BPs}$ and eIF4E, is frequently activated in a wide range of cancer types and could be a driver or malignancy, also for ovarian cancer ${ }^{[50-52]}$. Thus, targeting p70S6K using specific inhibitors already developed represents another alternative strategy against rapamycinresistant tumors ${ }^{[53]}$.

\section{TARGETING MTOR PROTEIN IN OVARIAN CANCER}

On the basis of the promising activity of these compounds on other cancer types, mTOR inhibitors have been tested on ovarian cancer ${ }^{[35,36,88]}$. Rapamycin treatment of several ovarian cancer cell lines resulted in a decrease in the phosphorylation levels of mTOR and $4 \mathrm{E}-\mathrm{BPs}$, together with an increase of $\mathrm{p}-\mathrm{AKT}^{[42]}$. These effects lead to an accumulation of eIF4E-4E-BPs complexes, which blocks protein translation and inhibits ovarian cancer cells proliferation ${ }^{[42]}$. Despite the above-mentioned promising results, rapamycin's clinical use is currently restricted due to adverse bioavailability ${ }^{[36]}$. The rapalogs Temsirolimus and Everolimus have been tested in clinical trials, showing anti-proliferative and antiangiogenic actions on ovarian cancer, especially when administrated in combination with carboplatin and paclitaxel ${ }^{[35,36]}$. However, as found in other cancers, the critical limitation of these inhibitors is the occurrence of resistance during the treatment, with a molecular mechanism that remains elusive. Loss of the negative feedback loops associated to $\mathrm{PI} 3 \mathrm{~K} / \mathrm{AKT} / \mathrm{mTOR}$ might trigger drug resistance mechanisms, one of which concerns the activation of mTORC2 that in turn activates AKT in response to mTORC1 inhibition ${ }^{[35]}$. In addition, differences in AKT 

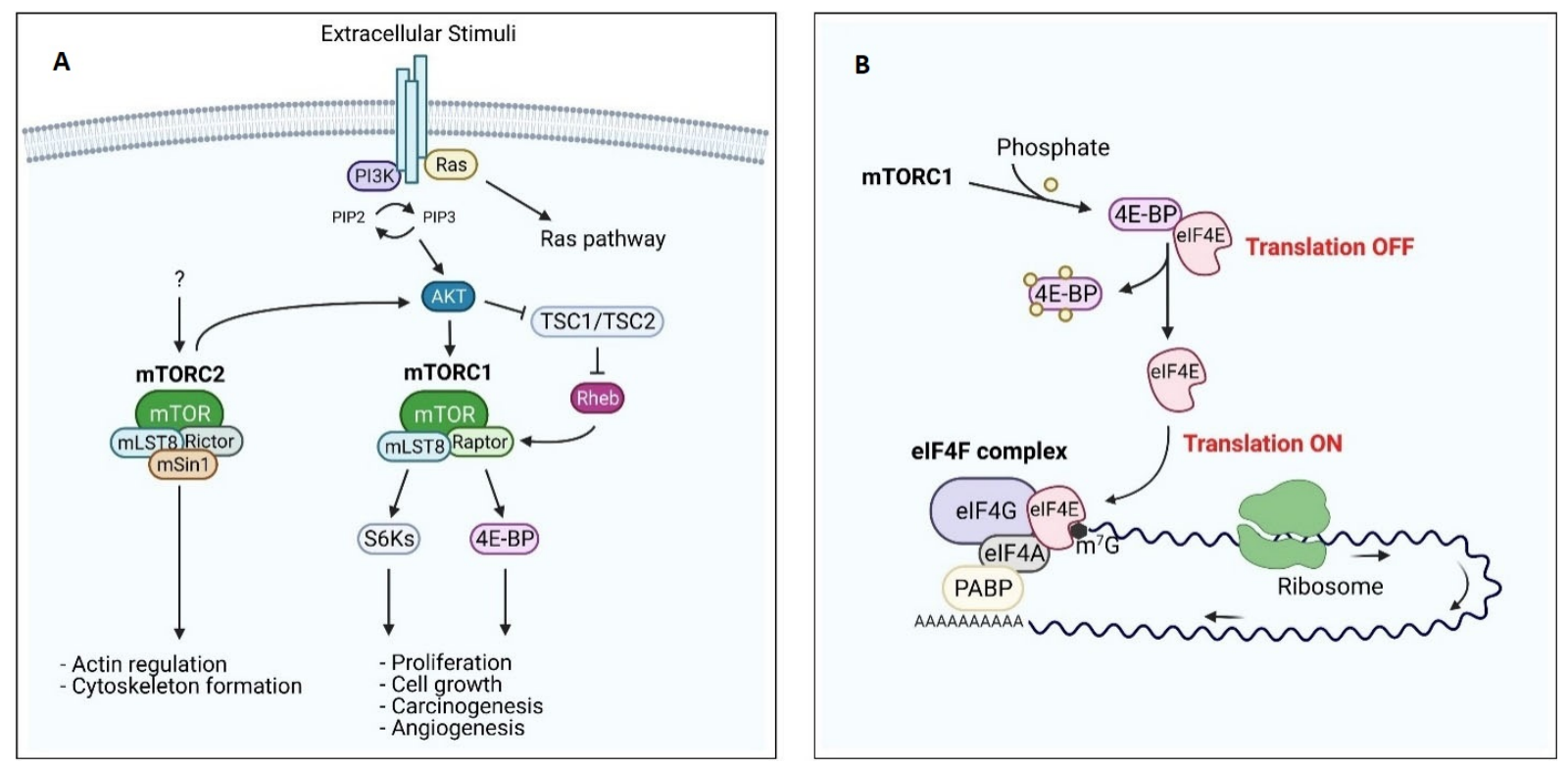

Figure 1. PI3K/mTOR pathway and regulation of elF4F complex. (A) PI3K and its downstream effectors AKT and mTOR are activated by many extracellular stimuli. The serine/threonine protein kinase mTOR forms, by association with several binding partners (mLST8, Raptor/Rictor, and mSIN1), 2 distinct complexes mTORC1 and mTORC2. mTORC2 activation leads to actin regulation and cytoskeleton organization, while mTORC1 allows the cap-dependent translation through the 4E-BPs phosphorylation, resulting in the dissociation of these proteins from elF4E. PI3K pathway dysregulation results in an altered proliferation, carcinogenesis, and angiogenesis. (B) The capbinding protein elF4E is released by $4 \mathrm{E}-\mathrm{BPs}$ as a result of its phosphorylation by $\mathrm{mTORC1}$, allowing elF $4 \mathrm{~F}$ complex formation and thus permitting translation of elF4E-sensitive mRNAs.

activity observed in different ovarian cancer cell lines contribute to the cell-specific sensitivity to pharmacological treatment by rapamycin and, more in general, by mTOR inhibitors ${ }^{[16]}$. In fact, as mentioned above, AKT signaling is the central hub of cellular proliferation and growth as well as activates alternative pathways ${ }^{[29]}$. Besides molecules able to target both mTORC1 and mTORC2 complexes, AZD2014 and AZD8055 have been tested in different ovarian cancer models, showing antitumor activities in combination with others drugs ${ }^{[57,58]}$.

Testing the effects of natural products in ovarian cancer therapy is of clinical interest. Resveratrol (3,4',5trihydroxy-trans-stilbene) is a polyphenol found in several plants and wines and thus naturally present in the human $\operatorname{diet}^{[89]}$. It has been shown to have anti-neoplastic effects on several types of carcinomas ${ }^{[00]}$, likely via inhibition of hypoxia-inducible factor $1 \alpha$ (HIF-1 $\alpha)$ and vascular endothelial growth factor ${ }^{[91]}$, both of which are expressed at higher levels in many human cancers, including ovarian cancer ${ }^{[11,92]}$. The mechanisms of inhibition by resveratrol are multiple; among them, its interference in the AKT/mTOR pathway, leading to a phosphorylation of S6K1 and 4E-BPs. Resveratrol also increases apoptosis and autophagy and decreases proliferation and invasiveness of ovarian cancer cells ${ }^{[93,94]}$.

Further strategies in the development of anti-cancer compounds targeting ovarian malignancies include the suppression of proteins that affect the mTOR cascade, using siRNA ${ }^{[95]}$, or the inactivation of AKT, PI3K, or simultaneous block of mTOR and PI3K, designing dual mTOR/PI3K inhibitors. Simultaneously targeting 2 kinases belonging to the same signaling pathway should lead to a more efficient inhibition of the $\mathrm{PI} 3 \mathrm{~K} / \mathrm{AKT} / \mathrm{mTOR}$ cascade and lower the probability of developing drug resistance. In addition, these compounds are developed to prevent AKT hyperactivation due to rapamycin or rapalog treatment ${ }^{[88]}$. The most clinically relevant dual drugs are PI-103, SF1126, GNE-477, XL765, and NVP-BEZ235, the latter being the only one that has been tested in a clinical trial ${ }^{[35,36,60,88]}$. In vitro and in vivo studies in ovarian cancer 
models have shown that these inhibitors decrease tumor cell growth and proliferation, also in combination with paclitaxel ${ }^{[96-98]}$. Interestingly, all these findings show that platinum resistance of ovarian cancer cells can be reversed by inhibiting mTOR (mTORC1/mTORC2), as specific mRNAs encoding survival, cell cycle, and other functions are inhibited ${ }^{[57,99]}$.

However, despite the promising results obtained targeting the mTOR pathway, there is a constant need to hunt for new molecular targets and therapeutic approaches. Therefore, the downstream mediator of mTOR pathway, the cap-dependent translation factor eIF4E, represents a valid candidate, being also a confluence point of multiple pathways.

\section{EIF4E INHIBITION: THE FUTURE OF OVARIAN CANCER THERAPY?}

Translation of proteins promoting cancer progression and invasiveness, such as kinases, transcription factors, and vascular growth factors, is mediated by the mRNA 5'-cap-binding complex, a heterotrimeric protein complex consisting of eIF4E, eIF4G, and eIF4A, which recruits the translation apparatus to the mRNA [Figure $1 \mathrm{~B}]^{[37]}$. eIF $4 \mathrm{G}$ acts as a scaffold protein, binding both the mRNA helicase eIF4A and eIF4E, while the function of eIF4E is to bind the $5^{\prime} 7$-methylguansine $\left(\mathrm{m}^{7} \mathrm{G}\right)$ mRNA cap, thereby selecting the mRNAs to be translated. Under normal conditions, eIF4E is expressed at low levels and is therefore the limiting factor in the formation of the cap-binding complex. Overexpression of eIF4E is, however, a signature of several aggressive cancer types, including triple-negative breast cancer and ovarian cancer $^{[100-106]}$. eIF4E undergoes phosphorylation at Ser209 by the mitogen-activated protein kinaseinteracting kinases 1 and $2(\mathrm{MNK} 1 / 2)$, which target the eIF4F complex ${ }^{[107,108]}$. Phosphorylation of eIF4E seems to have no functional role under physiological conditions ${ }^{[43,109]}$ but is an independent prognostic factor in several types of cancer ${ }^{[110]}$. The activity of eIF $4 \mathrm{E}$ is modulated by a heterogeneous group of $4 \mathrm{E}-\mathrm{BPs}$, phosphoproteins that compete with eIF $4 \mathrm{G}$ for the same binding site on eIF4E. When phosphorylated by the mTORC1 pathway, the affinity of $4 \mathrm{E}-\mathrm{BPs}$ for eIF4E decreases, facilitating translational initiation [Figure $1 \mathrm{~B}$ ]$^{[37]}$. Because of its tight control, a 2.5-fold increased expression of eIF4E is enough to induce transformation, metastatic progression, and suppression of apoptosis ${ }^{[102,111]}$. Conversely, more and more studies have shown that decreasing eIF4E levels in the cell reduces cell growth and invasiveness in several models of cancers ${ }^{[12-116]}$. It is therefore of utmost importance to develop drugs that hamper the activity of eIF4E by either reducing its expression and phosphorylation levels or competing with its biological partners, namely the $\mathrm{m}^{7} \mathrm{G}$ cap, eIF4G, and the $4 \mathrm{E}$-BPs [Table 1].

Because the activity of eIF4E is strictly dependent on its interaction with the mRNA cap, $\mathrm{m}^{7} \mathrm{G}$ analogs represent attractive drug candidates. By mimicking the mRNA cap structure, $m^{7} \mathrm{G}$ analogs compete for eIF $4 \mathrm{E}$ binding, thereby decreasing the rate of translation initiation. Ribavirin, an anti-viral drug commonly used to treat hepatitis $\mathrm{C}$, is a guanosine ribonucleoside analogue, initially characterized as cap-mimetic ${ }^{[76]}$, but this is controversial ${ }^{[77,78]}$. It was tested against acute myeloid leukemia ${ }^{[71,72]}$, ribavirin showed promising results in several cancer models, including breast and ovarian cancer ${ }^{[74,75,117]}$. Notably, even though eIF4E levels are not homogeneous among ovarian cancer cell lines and tissues, ribavirin treatment reduced the growth and survival of ovarian cancer cell lines and increased the efficacy of cisplatin treatment both in vitro and in vivo ${ }^{[74]}$, an observation that raises the possibility of combining it with other drugs for ovarian cancer therapy. Following the encouraging results obtained with ribavirin, several molecules extracted from $\mathrm{m}^{7} \mathrm{G}$ analog libraries have been selected for further studies. Among them, 7-benzyl guanosine monophosphate $(\mathrm{Bn} 7 \mathrm{GMP})^{[118]}$ and $4 \mathrm{Ei}-1^{[119]}$ are currently being studied in vitro and in vivo and might represent ideal adjuvants in ovarian cancer therapy ${ }^{[7,80,118,119]}$. 
The balance between active and inactive eIF4E is controlled by the relative abundance of $4 \mathrm{E}-\mathrm{BPs}$ and eIF $4 \mathrm{G}$ in the cell. Thus, to reduce the levels of eIF $4 \mathrm{E}$, drug design should focus on finding potential ligands able to outcompete cellular eIF4G and/or mimic the 4E-BPs. 4EGI-1, a small molecule discovered through highthroughput screening of compound libraries ${ }^{[8]}$, is an allosteric eIF4E inhibitor which binds eIF4E in a different region with respect to eIF $4 \mathrm{G}^{[82]}$, inhibiting eIF4G-eIF4E complex formation and facilitating the binding of $4 \mathrm{E}-\mathrm{BP}^{[120]}$. Furthermore, several short peptides have been designed, based on the sequence of eIF4E binding partners, to specifically destabilize the eIF4E-eIF4G complex in the cell, representing a valuable approach to target eIF4E-mediated translation in cancer models $s^{[8,87,121,122]}$. The increasing evidence that eIF4E targeting slows down cancer progression is having a prompt response in ovarian cancer research. Recently, a novel strategy to specifically target eIF4E activity in ovarian cancer models has been reported, where $4 \mathrm{E}-\mathrm{BP} 1$ peptides were fused to an agonist of the gonadotropin-releasing hormone $(\mathrm{GnRH})^{[84]}$, thereby mediating the uptake and showing a marked decrease in tumor cells growth.

Taken together, these studies suggest that eIF4E represents a promising candidate for the research on ovarian tumors, whereas downregulating eIF4E expression might be a useful and feasible approach to improve the therapeutic responsiveness of ovarian cancer. Future research effort must be employed in designing and testing potential drugs against eIF4E, to evaluate the possibility of a cancer-specific drug.

\section{CONCLUSION}

Patients diagnosed with ovarian cancer have poor prognosis, owing to the advanced status of malignancy at the time of diagnosis and the development of resistance to the standard therapy treatment. Thereby, new therapeutic strategies are urgently needed. The mTOR signaling pathway is frequently overactivated in ovarian cancer and converge to the increased levels of cap-dependent translation, being eIF4E the focal point of this pathway. Thus, specific inhibitors targeting mTOR and eIF4E represent promising and valid adjuvants for clinical management of ovarian cancer.

\section{DECLARATIONS}

\section{Authors' contributions}

The concept of the review was conceived by: Di Marino D, Romagnoli A

Wrote the manuscript: Romagnoli A, Maracci C

Supervision: Di Marino D, La Teana A

Prepared the figure: D’Agostino M

\section{Availability of data and materials}

Not applicable.

\section{Financial support and sponsorship}

Cristina Maracci was supported by Fondazione Umberto Veronesi.

\section{Conflicts of interest}

All authors declared that there are no conflicts of interest.

\section{Ethical approval and consent to participate}

Not applicable.

\section{Consent for publication}

Not applicable. 


\section{Copyright}

(C) The Author(s) 2021.

\section{REFERENCES}

1. Siegel RL, Miller KD, Jemal A. Cancer statistics, 2016. CA Cancer J Clin 2016;66:7-30. DOI PubMed

2. American Cancer Society, 2021 Available from: https://www.cancer.org/cancer/ovarian-cancer/about/key-statistics.html [Last accessed on 6 May 2021].

3. Yurkovetsky Z, Skates S, Lomakin A, et al. Development of a multimarker assay for early detection of ovarian cancer. J Clin Oncol 2010;28:2159-66. DOI PubMed PMC

4. Torre LA, Trabert B, DeSantis CE, et al. Ovarian cancer statistics, 2018. CA Cancer J Clin 2018;68:284-96. DOI PubMed PMC

5. Lloyd KL, Cree IA, Savage RS. Prediction of resistance to chemotherapy in ovarian cancer: a systematic review. BMC Cancer 2015;15:117. DOI PubMed PMC

6. Momenimovahed Z, Tiznobaik A, Taheri S, Salehiniya H. Ovarian cancer in the world: epidemiology and risk factors. Int $J$ Womens Health 2019;11:287-99. DOI PubMed PMC

7. Helm CW, States JC. Enhancing the efficacy of cisplatin in ovarian cancer treatment - could arsenic have a role. J Ovarian Res 2009;2:2. DOI PubMed PMC

8. Agarwal R, Kaye SB. Ovarian cancer: strategies for overcoming resistance to chemotherapy. Nat Rev Cancer 2003;3:502-16. DOI PubMed

9. Metzger-Filho O, Moulin C, D'Hondt V. First-line systemic treatment of ovarian cancer: a critical review of available evidence and expectations for future directions. Curr Opin Oncol 2010;22:513-20. DOI PubMed

10. Armstrong DK. Relapsed ovarian cancer: challenges and management strategies for a chronic disease. Oncologist 2002;7 Suppl 5:208. DOI PubMed

11. Bast RC Jr, Hennessy B, Mills GB. The biology of ovarian cancer : new opportunities for translation. Nat Rev Cancer 2009;9:415-28. DOI PubMed PMC

12. Eckstein N. Platinum resistance in breast and ovarian cancer cell lines. J Exp Clin Cancer Res 2011;30:91. DOI PubMed PMC

13. Damia G, Broggini M. Platinum Resistance in Ovarian Cancer: Role of DNA Repair. Cancers (Basel) 2019;11:119. DOI PubMed PMC

14. El-Shaimaa A. Arafa, Zhu Q, et al. Tangeretin Sensitizes Cisplatin-resistant Human Ovarian Cancer Cells through Down-regulation of PI3K/Akt Signaling Pathway. Cancer Res 2009;23:8910-7. DOI PubMed PMC

15. Chen SH, Chang JY. New Insights into Mechanisms of Cisplatin Resistance: From Tumor Cell to Microenvironment. Int J Mol Sci 2019;20:4136. DOI PubMed PMC

16. Xing D, Orsulic S. Modeling Resistance to Pathway-Targeted Therapy in Ovarian Cancer. Cell Cycle 2005;4:1004-6. DOI PubMed PMC

17. Rottenberg S, Disler C, Perego P. The rediscovery of platinum-based cancer therapy. Nat Rev Cancer 2021;21:37-50. DOI PubMed

18. Beale PJ, Rogers P, Boxall F, Sharp SY, Kelland LR. BCL-2 family protein expression and platinum drug resistance in ovarian carcinoma. Br J Cancer 2000;82:436-40. DOI PubMed PMC

19. Bieg D, Sypniewski D, Nowak E, Bednarek I. Morin decreases galectin-3 expression and sensitizes ovarian cancer cells to cisplatin. Arch Gynecol Obstet 2018;298:1181-94. DOI PubMed PMC

20. Mansouri A, Zhang Q, Ridgway LD, Tian L, Claret FX. Cisplatin resistance in an ovarian carcinoma is associated with a defect in programmed cell death control through XIAP regulation. Oncol Res 2003;13:399-404. DOI PubMed PMC

21. Li J, Feng Q, Kim JM, et al. Human ovarian cancer and cisplatin resistance: possible role of inhibitor of apoptosis proteins. Endocrinology 2001;142:370-80. DOI PubMed

22. Gordon AN, Fleagle JT, Guthrie D, Parkin DE, Gore ME, Lacave AJ. Recurrent epithelial ovarian carcinoma: a randomized phase III study of pegylated liposomal doxorubicin versus topotecan. J Clin Oncol 2001;19:3312-22. DOI PubMed

23. Mutch DG, Orlando M, Goss T, et al. Randomized phase III trial of gemcitabine compared with pegylated liposomal doxorubicin in patients with platinum-resistant ovarian cancer. J Clin Oncol 2007;25:2811-8. DOI PubMed

24. Gogineni V, Morand S, Staats H, et al. Current Ovarian Cancer Maintenance Strategies and Promising New Developments. J Cancer 2021;12:38-53. DOI PubMed PMC

25. Cortez AJ, Tudrej P, Kujawa KA, Lisowska KM. Advances in ovarian cancer therapy. Cancer Chemother Pharmacol 2018;81:17-38. DOI PubMed PMC

26. Tahmasebi S, Sonenberg N, Hershey JWB, Mathews MB. Protein Synthesis and Translational Control: A Historical Perspective. Cold Spring Harb Perspect Biol 2019;11:a035584. DOI PubMed PMC

27. Grzmil M, Hemmings BA. Translation regulation as a therapeutic target in cancer. Cancer Res 2012;72:3891-900. DOI PubMed

28. Liu GY, Sabatini DM. mTOR at the nexus of nutrition, growth, ageing and disease. Nat Rev Mol Cell Biol 2020;21:183-203. DOI PubMed PMC

29. Laplante M, Sabatini DM. mTOR signaling in growth control and disease. Cell 2012;149:274-93. DOI PubMed PMC

30. Grabiner BC, Nardi V, Birsoy K, et al. A diverse array of cancer-associated mTOR mutations are hyperactivating and can predict rapamycin sensitivity. Cancer Discov 2014;4:554-63. DOI PubMed PMC

31. Sabatini DM. mTOR and cancer: insights into a complex relationship. Nat Rev Cancer 2006;6:729-34. DOI PubMed

32. Fruman DA, Rommel C. PI3K and Cancer: Lessons, Challenges and Opportunities. Nat Rev Drug Discov 2014;13:140-56. DOI 
PubMed PMC

33. Cossa G, Lanzi C, Cassinelli G, et al. Differential outcome of MEK1/2 inhibitor-platinum combinations in platinum-sensitive and resistant ovarian carcinoma cells. Cancer Lett 2014;347:212-24. DOI PubMed

34. Deng J, Bai X, Feng X, et al. Inhibition of PI3K/Akt/mTOR signaling pathway alleviates ovarian cancer chemoresistance through reversing epithelial-mesenchymal transition and decreasing cancer stem cell marker expression. BMC Cancer 2019;19:618. DOI PubMed PMC

35. Mabuchi S, Kuroda H, Takahashi R, Sasano T. The PI3K/AKT/mTOR pathway as a therapeutic target in ovarian cancer. Gynecol Oncol 2015;137:173-9. DOI PubMed

36. Mabuchi S, Hisamatsu T, Kimura T. Targeting mTOR signaling pathway in ovarian cancer. Curr Med Chem 2011;18:2960-8. DOI PubMed

37. Siddiqui N, Sonenberg N. Signalling to eIF4E in cancer. Biochem Soc Trans 2015;43:763-72. DOI PubMed PMC

38. Hay N, Sonenberg N. Upstream and downstream of mTOR. Genes Dev 2004;18:1926-45. DOI PubMed

39. Bhat M, Robichaud N, Hulea L, Sonenberg N, Pelletier J, Topisirovic I. Targeting the translation machinery in cancer. Nat Rev Drug Discov 2015;14:261-78. DOI PubMed

40. Wendel HG, Silva RL, Malina A, et al. Dissecting eIF4E action in tumorigenesis. Genes Dev 2007;21:3232-7. DOI PubMed PMC

41. Zinzalla V, Stracka D, Oppliger W, Hall MN. Activation of mTORC2 by association with the ribosome. Cell 2011;144:757-68. DOI PubMed

42. Noske A, Lindenberg JL, Darb-esfahani S. Activation of mTOR in a subgroup of ovarian carcinomas : Correlation with p-eIF-4E and prognosis. Oncol Rep 2008;20:1409-17. PubMed

43. Lu C, Makala L, Wu D, Cai Y. Targeting translation: eIF4E as an emerging anticancer drug target. Expert Rev Mol Med 2016;18:e2. DOI PubMed

44. Li J, Kim SG, Blenis J. Rapamycin: one drug, many effects. Cell Metab 2014;19:373-9. DOI PubMed PMC

45. Hudes G, Carducci M, Tomczak P, et al; Global ARCC Trial. Temsirolimus, interferon alfa, or both for advanced renal-cell carcinoma. N Engl J Med 2007;356:2271-81. DOI

46. Rini BI. Temsirolimus, an inhibitor of mammalian target of rapamycin. Clin Cancer Res 2008;14:1286-90. DOI PubMed

47. Houghton PJ. Everolimus. Clin Cancer Res 2010;16:1368-72. DOI PubMed PMC

48. Mabuchi S, Altomare DA, Connolly DC, et al. RAD001 (Everolimus) delays tumor onset and progression in a transgenic mouse model of ovarian cancer. Cancer Res 2007;67:2408-13. DOI PubMed

49. Mita M, Sankhala K, Abdel-Karim I, Mita A, Giles F. Deforolimus (AP23573) a novel mTOR inhibitor in clinical development. Expert Opin Investig Drugs 2008;17:1947-54. DOI PubMed

50. Pópulo H, Lopes JM, Soares P. The mTOR signalling pathway in human cancer. Int J Mol Sci 2012;13:1886-918. DOI PubMed PMC

51. Pon YL, Zhou HY, Cheung AN, Ngan HY, Wong AS. p70 S6 kinase promotes epithelial to mesenchymal transition through snail induction in ovarian cancer cells. Cancer Res 2008;68:6524-32. DOI PubMed

52. Kurgan N, Tsakiridis E, Kouvelioti R, Moore J, Klentrou P, Tsiani E. Inhibition of Human Lung Cancer Cell Proliferation and Survival by Post-Exercise Serum Is Associated with the Inhibition of Akt, mTOR, p70 S6K, and Erk1/2. Cancers (Basel) 2017;9:46. DOI PubMed PMC

53. Ip CK, Wong AS. Exploiting p70 S6 kinase as a target for ovarian cancer. Expert Opin Ther Targets 2012;16:619-30. DOI PubMed

54. Lamming DW. Inhibition of the Mechanistic Target of Rapamycin (mTOR)-Rapamycin and Beyond. Cold Spring Harb Perspect Med 2016;6:a025924. DOI PubMed PMC

55. Thoreen CC, Sabatini DM. Rapamycin inhibits mTORC1, but not completely. Autophagy 2009;5:725-6. DOI

56. Hsieh AC, Liu Y, Edlind MP, et al. The translational landscape of mTOR signalling steers cancer initiation and metastasis. Nature 2013;485:55-61. DOI PubMed PMC

57. Hsieh AC, Liu Y, Edlind MP, et al. The translational landscape of mTOR signalling steers cancer initiation and metastasis. Nature 2012;485:55-61. DOI

58. Wong Te Fong AC, Thavasu P, Gagrica S, et al. Evaluation of the combination of the dual m-TORC1/2 inhibitor vistusertib (AZD2014) and paclitaxel in ovarian cancer models. Oncotarget 2017;8:113874-84. DOI PubMed PMC

59. Zou ZQ, Zhang XH, Wang F, et al. A novel dual PI3Kalpha/mTOR inhibitor PI-103 with high antitumor activity in non-small cell lung cancer cells. Int J Mol Med 2009;24:97-101. DOI PubMed

60. Maira SM, Stauffer F, Brueggen J, et al. Identification and characterization of NVP-BEZ235, a new orally available dual phosphatidylinositol 3-kinase/mammalian target of rapamycin inhibitor with potent in vivo antitumor activity. Mol Cancer Ther 2008;7:1851-63. DOI PubMed

61. Garlich JR, De P, Dey N, et al. A vascular targeted pan phosphoinositide 3-kinase inhibitor prodrug, SF1126, with antitumor and antiangiogenic activity. Cancer Res 2008;68:206-15. DOI PubMed

62. Heffron TP, Berry M, Castanedo G, et al. Identification of GNE-477, a potent and efficacious dual PI3K/mTOR inhibitor. Bioorg Med Chem Lett 2010;20:2408-11. DOI PubMed

63. Yu K, Toral-Barza L, Shi C, et al. Biochemical, cellular, and in vivo activity of novel ATP-competitive and selective inhibitors of the mammalian target of rapamycin. Cancer Res 2009;69:6232-40. DOI PubMed

64. Duffy AG, Makarova-Rusher OV, Ulahannan SV, et al. Modulation of tumor eIF4E by antisense inhibition: A phase I/II translational clinical trial of ISIS 183750-an antisense oligonucleotide against eIF4E-in combination with irinotecan in solid tumors and irinotecan-refractory colorectal cancer. Int J Cancer 2016;139:1648-57. DOI PubMed PMC 
65. Hong DS, Kurzrock R, Oh Y, et al. A phase 1 dose escalation, pharmacokinetic, and pharmacodynamic evaluation of eIF-4E antisense oligonucleotide LY2275796 in patients with advanced cancer. Clin Cancer Res 2011;17:6582-91. DOI PubMed PMC

66. Jiang CC, Croft A, Tseng HY, et al. Repression of microRNA-768-3p by MEK/ERK signalling contributes to enhanced mRNA translation in human melanoma. Oncogene 2014;33:2577-88. DOI PubMed

67. Liu S, Zha J, Lei M. Inhibiting ERK/Mnk/eIF4E broadly sensitizes ovarian cancer response to chemotherapy. Clin Transl Oncol 2018;20:374-81. DOI PubMed

68. Diab S, Kumarasiri M, Yu M, et al. MAP kinase-interacting kinases--emerging targets against cancer. Chem Biol 2014;21:441-52. DOI PubMed

69. Altman JK, Szilard A, Konicek BW, et al. Inhibition of Mnk kinase activity by cercosporamide and suppressive effects on acute myeloid leukemia precursors. Blood 2013;121:3675-81. DOI PubMed PMC

70. Hofmann WP, Herrmann E, Sarrazin C, Zeuzem S. Ribavirin mode of action in chronic hepatitis C: from clinical use back to molecular mechanisms. Liver Int 2008;28:1332-43. DOI PubMed

71. Assouline S, Culjkovic B, Cocolakis E, et al. Molecular targeting of the oncogene eIF4E in acute myeloid leukemia (AML): a proofof-principle clinical trial with ribavirin. Blood 2009;114:257-60. DOI PubMed

72. Borden KL, Culjkovic-Kraljacic B. Ribavirin as an anti-cancer therapy: acute myeloid leukemia and beyond? Leuk Lymphoma 2010;51:1805-15. DOI PubMed PMC

73. Casaos J, Gorelick NL, Huq S, et al. The Use of Ribavirin as an Anticancer Therapeutic: Will It Go Viral? Mol Cancer Ther 2019;18:1185-94. DOI PubMed

74. Jin J, Xiang W, Wu S, Wang M, Xiao M, Deng A. Targeting eIF4E signaling with ribavirin as a sensitizing strategy for ovarian cancer. Biochem Biophys Res Commun 2019;510:580-6. DOI PubMed

75. Dai D, Chen H, Tang J, Tang Y. Inhibition of mTOR/eIF4E by anti-viral drug ribavirin effectively enhances the effects of paclitaxel in oral tongue squamous cell carcinoma. Biochem Biophys Res Commun 2017;482:1259-64. DOI PubMed

76. Kentsis A, Topisirovic I, Culjkovic B, Shao L, Borden KL. Ribavirin suppresses eIF4E-mediated oncogenic transformation by physical mimicry of the 7-methyl guanosine mRNA cap. Proc Natl Acad Sci U S A 2004;101:18105-10. DOI

77. Yan Y, Svitkin Y, Lee JM, Bisaillon M, Pelletier J. Ribavirin is not a functional mimic of the 7-methyl guanosine mRNA cap. RNA 2005;11:1238-44. DOI

78. Westman B, Beeren L, Grudzien E, et al. The antiviral drug ribavirin does not mimic the 7-methylguanosine moiety of the mRNA cap structure in vitro. $R N A$ 2005;11:1505-13. DOI

79. Chen EZ, Jacobson BA, Patel MR, et al. Small-molecule inhibition of oncogenic eukaryotic protein translation in mesothelioma cells. Invest New Drugs 2014;32:598-603. DOI PubMed

80. Li S, Jia Y, Jacobson B, et al. Treatment of breast and lung cancer cells with a N-7 benzyl guanosine monophosphate tryptamine phosphoramidate pronucleotide (4Ei-1) results in chemosensitization to gemcitabine and induced eIF4E proteasomal degradation. Mol Pharm 2013;10:523-31. DOI PubMed PMC

81. Moerke NJ, Aktas H, Chen H, et al. Small-molecule inhibition of the interaction between the translation initiation factors eIF4E and eIF4G. Cell 2007;128:257-67. DOI PubMed

82. Papadopoulos E, Jenni S, Kabha E, et al. Structure of the eukaryotic translation initiation factor eIF4E in complex with 4EGI-1 reveals an allosteric mechanism for dissociating eIF4G. Proc Natl Acad Sci U S A 2014;111:E3187-95. DOI PubMed PMC

83. Cencic R, Hall DR, Robert F, et al. Reversing chemoresistance by small molecule inhibition of the translation initiation complex eIF4F. Proc Natl Acad Sci U S A 2011;108:6689. DOI PubMed PMC

84. Ko SY, Guo H, Barengo N, Naora H. Inhibition of ovarian cancer growth by a tumor-targeting peptide that binds eukaryotic translation initiation factor 4E. Clin Cancer Res 2009;15:4336-47. DOI PubMed

85. Lama D, Quah ST, Verma CS, et al. Rational optimization of conformational effects induced by hydrocarbon staples in peptides and their binding interfaces. Sci Rep 2013;3:3451. DOI PubMed PMC

86. Lama D, Quah ST, Brown CJ, Lane DP, Verma CS. 159 Stapled-peptides targeting the protein-binding interface of eukaryotic Translation Initiation Factor 4E (eIF4E) protein. J Biomol Struct Dyn 2015;33:102-3. DOI

87. Lama D, Liberatore AM, Frosi Y, et al. Structural insights reveal a recognition feature for tailoring hydrocarbon stapled-peptides against the eukaryotic translation initiation factor 4E protein. Chem Sci 2019;10:2489-500. DOI PubMed PMC

88. Mazzoletti M, Broggini M. PI3K/AKT/mTOR inhibitors in ovarian cancer. Curr Med Chem 2010;17:4433-47. DOI PubMed

89. Langcake P, Pryce RJ. The production of resveratrol and the viniferins by grapevines in response to ultraviolet irradiation. Phytochemistry 1977;16:1193-6. DOI

90. Jang M, Cai L, Udeani GO, et al. Cancer chemopreventive activity of resveratrol, a natural product derived from grapes. Science 1997;275:218-20. DOI PubMed

91. Cao Z, Fang J, Xia C, Shi X, Jiang BH. trans-3,4,5'-Trihydroxystibene inhibits hypoxia-inducible factor 1alpha and vascular endothelial growth factor expression in human ovarian cancer cells. Clin Cancer Res 2004;10:5253-63. DOI PubMed

92. Zhong H, De Marzo AM, Laughner E, et al. Overexpression of Hypoxia-inducible Factor $1 \alpha$ in Common Human Cancers and Their Metastase. Cancer Res 2000;59:5830-5. PubMed

93. Zhong LX, Zhang Y, Wu ML, et al. Resveratrol and STAT inhibitor enhance autophagy in ovarian cancer cells. Cell Death Discov 2016;2:15071. DOI PubMed PMC

94. Stakleff KS, Sloan T, Blanco D, Marcanthony S, Booth TD, Bishayee A. Resveratrol exerts differential effects in vitro and in vivo against ovarian cancer cells. Asian Pac J Cancer Prev 2012;13:1333-40. DOI PubMed

95. Altman MK, Alshamrani AA, Jia W, et al. Suppression of the GTPase-activating protein RGS10 increases Rheb-GTP and mTOR 
signaling in ovarian cancer cells. Cancer Lett 2015;369:175-83. DOI PubMed PMC

96. Lheureux S, Lecerf C, Briand M, et al. (18)F-FDG Is a Surrogate Marker of Therapy Response and Tumor Recovery after Drug Withdrawal during Treatment with a Dual PI3K/mTOR Inhibitor in a Preclinical Model of Cisplatin-Resistant Ovarian Cancer. Transl Oncol 2013;6:586-95. DOI PubMed PMC

97. Fabi F, Adam P, Parent S, Tardif L, Cadrin M, Asselin E. Pharmacologic inhibition of Akt in combination with chemotherapeutic agents effectively induces apoptosis in ovarian and endometrial cancer cell lines. Mol Oncol 2020. DOI PubMed

98. Hu L, Hofmann J, Lu Y, Mills GB, Jaffe RB. Inhibition of phosphatidylinositol 3'-kinase increases efficacy of paclitaxel in in vitro and in vivo ovarian cancer models. Cancer Res 2002;62:1087-92. PubMed

99. David-West G, Ernlund A, Gadi A, Schneider RJ. mTORC1/2 inhibition re-sensitizes platinum-resistant ovarian cancer by disrupting selective translation of DNA damage and survival mRNAs. Oncotarget 2018;9:33064-76. DOI PubMed PMC

100. Jacobson BA, Alter MD, Kratzke MG, et al. Repression of cap-dependent translation attenuates the transformed phenotype in nonsmall cell lung cancer both in vitro and in vivo. Cancer Res 2006;66:4256-62. DOI PubMed

101. Pelletier J, Graff J, Ruggero D, Sonenberg N. Targeting the eIF4F translation initiation complex: a critical nexus for cancer development. Cancer Res 2015;75:250-63. DOI PubMed PMC

102. Graff JR, Zimmer SG. Translational control and metastatic progression: Enhanced activity of the mRNA cap-binding protein eIF-4E selectively enhances translation of metastasis-related mRNAs. Clin Exp Metastasis 2003;20:265-73. DOI PubMed

103. Pettersson F, Del Rincon SV, Emond A, et al. Genetic and pharmacologic inhibition of eIF4E reduces breast cancer cell migration, invasion, and metastasis. Cancer Res 2015;75:1102-12. DOI PubMed

104. Asimomytis A, Karanikou M, Rodolakis A, et al. mTOR downstream effectors, 4EBP1 and eIF4E, are overexpressed and associated with HPV status in precancerous lesions and carcinomas of the uterine cervix. Oncol Lett 2016;12:3234-40. DOI PubMed PMC

105. Yang S, Hewitt S, Steinberg S, Liewehr D, Swain S. Expression levels of eIF4E, VEGF, and cyclin D1, and correlation of eIF4E with VEGF and cyclin D1 in multi-tumor tissue microarray. Oncol Rep 2007;17:281-7. PubMed

106. Zheng J, Li X, Zhang C, Zhang Y. eIF4E Overexpression Is Associated with Poor Prognoses of Ovarian Cancer. Anal Cell Pathol (Amst) 2020;2020:8984526. DOI PubMed PMC

107. Ueda T, Watanabe-Fukunaga R, Fukuyama H, Nagata S, Fukunaga R. Mnk2 and Mnk1 are essential for constitutive and inducible phosphorylation of eukaryotic initiation factor 4E but not for cell growth or development. Mol Cell Biol 2004;24:6539-49. DOI PubMed PMC

108. Waskiewicz AJ, Johnson JC, Penn B, Mahalingam M, Kimball SR, Cooper JA. Phosphorylation of the cap-binding protein eukaryotic translation initiation factor 4E by protein kinase Mnk1 in vivo. Mol Cell Biol 1999;19:1871-80. DOI PubMed PMC

109. McKendrick L, Morley SJ, Pain VM, Jagus R, Joshi B. Phosphorylation of eukaryotic initiation factor 4E (eIF4E) at Ser209 is not required for protein synthesis in vitro and in vivo. Eur J Biochem 2001;268:5375-85. DOI PubMed

110. Carter JH, Deddens JA, Spaulding NR IV, et al. Phosphorylation of eIF4E serine 209 is associated with tumour progression and reduced survival in malignant melanoma. Br J Cancer 2016;114:444-53. DOI PubMed PMC

111. Schneider RJ, Sonenberg N. Translational Control in Cancer Development and Progression. Cold Spring Harb Monogr Arch 2007;48:401. DOI

112. Wan J, Shi F, Xu Z, Zhao M. Knockdown of eIF4E suppresses cell proliferation, invasion and enhances cisplatin cytotoxicity in human ovarian cancer cells. Int J Oncol 2015;47:2217-25. DOI PubMed

113. Zhan Y, Dahabieh MS, Rajakumar A, et al. The role of eIF4E in response and acquired resistance to vemurafenib in melanoma. $J$ Invest Dermatol 2015;135:1368-76. DOI PubMed

114. Zhou FF, Yan M, Guo GF, et al. Knockdown of eIF4E suppresses cell growth and migration, enhances chemosensitivity and correlates with increase in Bax/Bcl-2 ratio in triple-negative breast cancer cells. Med Oncol 2011;28:1302-7. DOI PubMed

115. Choi CH, Lee JS, Kim SR, et al. Direct inhibition of eIF4E reduced cell growth in endometrial adenocarcinoma. J Cancer Res Clin Oncol 2011;137:463-9. DOI PubMed

116. Cao J, Sun X, Zhang X, Chen D. Inhibition of eIF4E cooperates with chemotherapy and immunotherapy in renal cell carcinoma. Clin Transl Oncol 2018;20:761-7. DOI PubMed

117. Pettersson F, Yau C, Dobocan MC, et al. Ribavirin treatment effects on breast cancers overexpressing eIF4E, a biomarker with prognostic specificity for luminal B-type breast cancer. Clin Cancer Res 2011;17:2874-84. DOI PubMed PMC

118. Jia Y, Chiu TL, Amin EA, Polunovsky V, Bitterman PB, Wagner CR. Design, synthesis and evaluation of analogs of initiation factor 4E (eIF4E) cap-binding antagonist Bn7-GMP. Eur J Med Chem 2010;45:1304-13. DOI PubMed PMC

119. Ghosh B, Benyumov AO, Ghosh P, et al. Nontoxic chemical interdiction of the epithelial-to-mesenchymal transition by targeting capdependent translation. ACS Chem Biol 2009;4:367-77. DOI PubMed PMC

120. Sekiyama N, Arthanari H, Papadopoulos E, Rodriguez-Mias RA, Wagner G, Léger-Abraham M. Molecular mechanism of the dual activity of 4EGI-1: Dissociating eIF4G from eIF4E but stabilizing the binding of unphosphorylated 4E-BP1. Proc Natl Acad Sci U S A 2015;112:E4036-45. DOI PubMed PMC

121. Marino D, Chillemi G, De Rubeis S, Tramontano A, Achsel T, Bagni C. MD and Docking Studies Reveal That the Functional Switch of CYFIP1 is Mediated by a Butterfly-like Motion. J Chem Theory Comput 2015;11:3401-10. DOI PubMed

122. Marino D, D'Annessa I, Tancredi H, Bagni C, Gallicchio E. A unique binding mode of the eukaryotic translation initiation factor 4E for guiding the design of novel peptide inhibitors. Protein Sci 2015;24:1370-82. DOI PubMed PMC 